favourably, on choice, against medically trained analysts.

Senior registrars will need to address a difficult balance: College (JCHPT) guidelines, which fit comfortably lucrative private practice; the needs of varied and sizeable catchment populations; the economic pressure of the developing "market" in health care. There can be few medical psychotherapists who are not afflicted by, or witnessing paranoid anxieties, in these uncertain times.

The medical psychotherapeutic community and its potential clientele have two reasons for thanking Dr Ryle (Psychiatric Bulletin, January 1992, 16, 30-32); for his good sense in the Bulletin and for having elucidated cognitive analytic therapy, which can serve as a realistic bridge between ideology and reality. I wish Dr Caldicott and her committee every success in their deliberations on these vitally important matters.

DENNIS P. FlanNERY

Leeds Health Authority and

Leeds University

\section{Psychiatric services for old people in the UK and Australia}

DeAR Sirs

Professor Andrews' response to Dr Snowdon and myself (Psychiatric Bulletin, January 1992, 16, 4849) that "the elderly themselves are suspicious of mental health services, fearing institutionalisation in a mental hospital. They therefore (my italics) seek mental health care from general practitioners and geriatricians". There is no factual foundation for this statement. Having recently visited services in Australia, I believe that older patients do not seek help from psychiatrists primarily because it is often not available.

I disagree that there are no means to decide whether predominant Australian or British models are best. Studies comparing specialised and non-specialised services in Britain (Wattis, 1989) generally show specialist old age psychiatry services to be better. Also, I have listened to grumbles of Australian geriatricians about psychiatrists' unwillingness to be involved with elderly patients. There are also areas of Australia where psychogeriatric services have developed and these could be compared with areas where such services are not available.

Finally, there are two fallacies in Professor Andrews' final sentence. Firstly, even if nursing home care is cheaper per person it is not cheaper overall if a substantially larger proportion of the elderly population is placed in such care. Secondly, good specialist psychogeriatric services have potentially cost saving functions (e.g. identifying and treating depressive illness in the community, so avoiding nursing home care) and are not necessarily associ- ated with placement of patients in long-stay mental hospital care.

\section{St James's University Hospital \\ Leeds LS9 $7 T F$}

JOHN P. WATtIS

\section{Reference}

WaTtis, J. (1989) A comparison of "specialised" and "nonspecialised" psychiatric services for old people in the United Kingdom. International Journal of Geriatric Psychiatry, 4, 59-62.

\section{Managing a challenging case}

\section{DeAr Sirs}

I was intrigued by Drs Joyce and Palia's correspondence inviting suggestions on management for their challenging case (Psychiatric Bulletin, January 1992 , 16, 52).

Though brief, the history reveals a married 68year-old woman (S.T.) who presumably has a family. She has had frequent admissions to the same hospital over a period of 34 years, which suggests that she has repeatedly entrusted her care to the medical staff who in turn have developed a working relationship addressing her needs. Her current diagnosis is unclear. She appears to have chronic schizophrenia with depressive features now prominent. I am unsure whether her lack of insight refers to the ongoing schizophrenia or the more recent depression. Her cognitive functioning is impaired which may be due to the depression, the presence of an early dementing process or environmental factors. She is obviously not capable of independent living, being resident on a long stay ward. The presence of a bladder calculus exposes her to repeated urinary tract infections, leaves her anaemic and on analgesic medication. Anti-cholinergic side-effects of her psychiatric medications pose future risks to her in addition to the more obvious consequences of leaving the calculus in situ.

Central to the authors' dilemma is the conflict between the autonomy of their patient and their duty of care to her. If they follow a paternalistic line, should they consider S.T. to be competent but misguided and therefore arrange the operation because its in her best interests? Or should they consider S.T. as incompetent by virtue of the fact that she is making an illogical decision in refusing the operation? Either of the above choices leaves them running the risk of being held guilty of trespass to the person, but equally if they withhold that treatment, they may be in breach of a duty of care owed to S.T.

In S.T.'s case the interpretation of her wishes is uncertain, considering her history, current mental state and her physical health. A judgement has to be made on her behalf and despite her wishes being clear, I feel it is appropriate to do so. S.T. appears to 
have established a trusting relationship with her psychiatric carers over a 34 year period and the authors must now bear that responsibility. In May 1989, Lord Brandon summarised the Law Lords' decision: "in many cases ... it will not only be lawful for doctors, on the grounds of necessity, to operate on or give other medical treatment to adult patients disabled from giving their consent: it will also be their common law duty to do so." This has been incorporated into the Code of Practice which gives a list of indications for when treatment can be given without consent. The fourth indication (15.8.d.) "otherwise incapable and in need of medical care in circumstances in which he has not declared his unwillingness to be treated prior to the onset of the incapacitating condition," is a very clear indication of how the authors should proceed.

In conclusion, I would manage the case as follows. Firstly, I would review the psychiatric diagnosis and appraise myself of the long-term medical risks if the bladder calculus is left to its own devices. I would then consult with S.T.'s family, her current carers and my peers, followed by an inter-disciplinary case conference with my surgical colleagues and a discussion with the local ethics committee. Hopefully, this would convince all those concerned and particularly the surgeon that the decision to operate was both legally and ethically correct.

RAYMOND F. TRAVERS

The Scott Clinic

Rainhill Hospital,

Prescot, Merseyside

L35 $4 P Q$

\section{A psychiatrist with beds ...}

DeAR SIRS

Professor Cox's excellent article (Psychiatric Bulletins $1991,15,684-686)$ prompts me to report on a recent survey in our district of general practitioners in which they were asked to name three key elements which they felt a psychiatric service should provide.

These were, in order of importance:

(a) rapid response to acute psychiatric crises, with the ability to admit patients whenever necessary to the psychiatric wards of our DGH unit

(b) skilled consultant assessment of psychiatric out-patient referrals

(c) provision of speedy counselling and psychotherapy services when necessary.

It is perhaps ironic that the newest specialist section of the College, and one that is perhaps most uncertain of its identity, represents the service that is most highly valued by general practitioners. My impression is that, so far from being generals, most general psychiatrists feel more like foot soldiers!
Perhaps the first war that needs to be waged is that of semantics. In our district we resolutely resist the dichotomising of 'hospital' and 'community' and insist that the hospital is part of the community. One only has to pass through the hospital foyer on a busy day or to try to find parking space in the hospital car park to see the truth of this.

I suggest the general psychiatry section seriously considers renaming itself 'Section of Acute Psychiatry' or alternatively merging (federally of course) with the Social and Community Psychiatry section.

\section{North Devon District Hospital \\ Barnstaple EX31 4JB} JEREMY HOLMES

\section{DeAr SirS}

The results of Dr Jeremy Holme's survey of his District's general practitioners in which they were asked the name of those elements which they felt a psychiatric service should provide, causes us no surprises. Interestingly, a recent survey done by Dr Tom Burns, Secretary of the Community Psychiatry Section, revealed similar findings. General practitioners require a speedy response to acute psychiatric crises as they are wont to receiving from our general physician and surgical colleagues. GPs are aware of the pitfalls of psychiatric diagnosis and further, regret the over-emphasis on medication and welcome the access that psychiatrists have to counselling and psychotherapy services.

Dr Holme's second point is more problematical. Like him, we resist the dichotomy of hospital and community. We also accept that there is at least a debate that the General Psychiatry Section might merge with the Social and Community Psychiatry Section. Federalism, as our political masters have repeatedly pointed out, has different meanings for different people. If such a merger was to be considered, then, perhaps a confederation would be more relevant, each Section retaining considerable autonomy.

We recognise that the Section of General Psychiatry is not a good term and claim no responsibility for this title. Nevertheless, the name of our Section has not deterred over 3,000 Members and Fellows of the College from signing up. Unfortunately, other titles may be worse and Dr Holmes's suggestion that we should be re-christened the "Section of Acute Psychiatry" would probably irritate our Community and Social Psychiatry colleagues - and child psychiatrists may not be happy either. Perhaps a Section of General Adult Psychiatry would better represent our clinical interests with regard to the age of our patients and the specialist skills we possess. We would welcome the advice of your readers.

JoHN L. Cox (Chairman)

J. HuBert LACEY (Secretary) General Psychiatry Section 